about one-third of the fish, which serve as the test subjects. But he anticipates that it will be ten years before it's adopted.

Often, a catalysing event piques policymakers' appetite for scientific evidence. That's why scientists should make a longterm investment in policy work, Evans says, and be ready to act when the opportunity arises. For instance, she recalls, the Australian government decided to implement the biodiversity-offsets project when a new minister took office, and drew on well-established research. "We ended up being able to use that science really quickly." Evans adds that researchers should pay attention to changes in administrations in their own and other jurisdictions that might increase the receptiveness of policymakers to scientific evidence.

There can be cases, however, when the evidence isn't yet strong enough to spur action, says Ian Boyd, chief scientific adviser at the UK Department for Environment, Food and Rural Affairs. For example, he says, research over the past decade on whether neonicotinoid pesticides harm bees hasn't yielded clear answers about population-level effects. In an opinion article earlier this year, Boyd explained he had become convinced that the chemicals were being used more widely than was recognized and offered growers only a marginal benefit ${ }^{4}$. However, he lamented the lack of rigorous studies quantifying the actual danger they posed to pollinators. The United Kingdom ultimately backed the EU's decision to ban the chemicals.

To make sure science influences policy, it's best to collaborate with policymakers from the start, says Mach. "Scientists doing science in isolation won't know what questions are most relevant, and also won't really influence decisions," she says. Collaboration requires reaching out to policymakers and agency staff long before research begins, listening closely to their questions and needs, and shaping studies around those. After that, she says, scientists must maintain regular contact, share preliminary results and be ready to change the focus of a research project in response to feedback.

It's challenging, but Mach and others find working at the interface of science and policy extremely rewarding. After all, like many researchers, Mach went into science eager to tackle issues that matter. "There's something that's really motivating about doing science that is attuned to the bigger picture," she says. -

Julia Rosen is a freelance writer in Portland, Oregon.

1. Evans, M. C. \& Cvitanovic, C. Palgrave Commun. 4, 88 (2018).

2. Downs, C. A. et al. Arch. Environ. Contam. Toxicol. 70, 265-288 (2016).

3 Rose, D. C. Br. Ecol. Soc. Bull. 48 (4), 34-35 (2017).

4. Boyd, I. L. Nature Ecol. Evol. 2, 920-921 (2018).

\title{
Stronger together
}

\section{Lab heads should foster collaborative research, say Katherine D. Kinzler and Kristin Shutts.}

$\mathrm{T}$ wo of our $\mathrm{PhD}$ students were in a bind. They had collaborated on a research project that merged their interests and, as counselled by other faculty members, had decided early in the research process on authorship order. But by the end of the partnership, the designated second author felt that she had contributed more time and expertise to the project, and wanted to switch the authorship order. The would-be first author disagreed, pointing to their earlier arrangement. Disappointment, or worse, seemed the probable outcome.

This scenario might feel familiar to many principal investigators (PIs). At best, considering contribution and authorship order can be stressful for students and postdocs who collaborate; at worst, these issues can prevent alliances from developing at all. Yet, in our experience, as student collaborators ourselves and then as PIs, some of the best science - and the impetus for growth in junior researchers' careers - comes from collaborative efforts between graduate students and/or postdocs. As PIs, we work to set the tone for joint science to flourish in our labs.

We began our own collaboration as $\mathrm{PhD}$ students in the same lab at Harvard University in Cambridge, Massachusetts. Working together has produced positive outcomes for both of us - from developing more-advanced records for the job market (then) to receiving a multi-year federal grant from the US National Institutes of Health that we jointly administer (now). Most importantly, we've come to believe that the ideas we generate as a two-person team are better than what either of us would produce alone, and that the scientific process is more fun to conduct together.

Consequently, we were surprised to encounter push-back when we suggested in our own labs that students consider working together. So, we developed a model to foster collaboration.

Eliminate a 'zero-sum' mindset. Collaboration can help to direct students to 'growing the pie' - creating more resources together that they can ultimately share. As graduate students, we developed a shared research programme that generated multiple studies and articles, so determining authorship was never stressful for us. We encouraged the students in the anecdote above to think about generating a pipeline of collaborative projects. By treating the project as the first step in an important, long-term programme, neither student felt as worried about the final authorship decision.

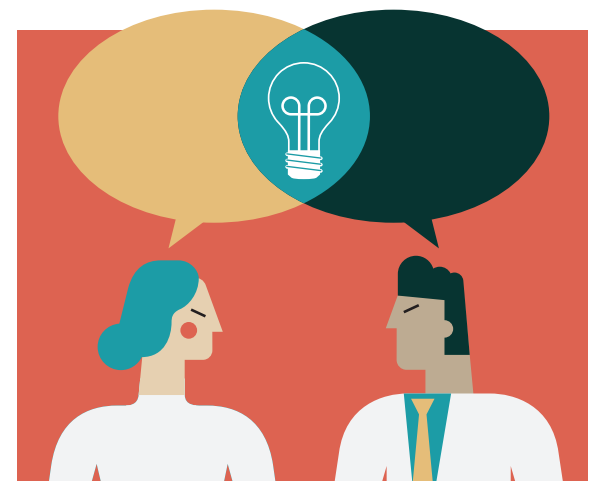

Establish parameters. Recently, a new student in one of our labs wanted to collaborate with a postdoc, yet devoted significant attention to dissecting her role in the project and how much time she (compared with the postdoc) was spending on it. All this worry risked stagnating the science and ending the collaboration. We explained the benefits of this type of partnership, and pointed to how our own successes, as well as those of previous students, have been bolstered by sharing credit with other scientists.

Encourage students to make authorship decisions after they collect data. In our experience, determining authorship later in the process puts the science (rather than the publication process) front and centre, and helps students to think of growing the total amount of research, rather than angsting over whether they plan to contribute $49 \%$ or $51 \%$ of any given project.

Of course, we recognize that collaboration might not work for all student pairs. Collaborative relationships, in our experience, are most likely to flourish when junior researchers lead them. PIs should help students and postdocs understand the value and process of collaborative work. But junior scientists should initiate specific collaborative projects and decide together how to carry out the research.

"Let's put the science ahead of ourselves," agreed our two students deciding on authorship order. One was first author on the initial paper - which sparked a new research programme and the other was first author on a subsequent publication. Collaboration benefits both the students and the science.

Katherine D. Kinzler is a psychologist at Cornell University in Ithaca, New York. Kristin Shutts is a psychologist at the University of Wisconsin-Madison. 